\title{
European economic \\ governance and the 2017 \\ European Semester cycle
}

MANICA HAUPTMAN, MSc

Conference introductory note*

https://doi.org.10.3326/pse.41.1.4

\footnotetext{
* Received: February 1, 2017

Accepted: February 6, 2017
}

A conference introductory note was held at the conference Public Sector Economics organized by the Institute of Public Finance and Friedrich-Ebert-Stiftung in Zagreb on October 14-15, 2016.

Manica HAUPTMAN

Economic Counsellor and European Semester Officer, European Commission, Representation in Croatia, Ulica Augusta Cesarca 4, 10000 Zagreb, Croatia e-mail: Manica.HAUPTMAN@ec.europa.eu 
The purpose of this note is to present economic governance in the European Union, its 2017 cycle and its main tools for the coordination of economic and fiscal policies of the 28 member states through a list of parallel procedures and processes.

The 2008 economic and financial crisis exposed the weaknesses of EU economic governance and resulted in a debate on how to find a balance between intergovernmental and community methods, also questioning further the use of soft intergovernmental methods. The answer came in a wide range of measures resulting in an integrated system of coordination and surveillance of EU economic policies, in the form of an annual cycle called the "European Semester". It is based on two legislative packages strengthening fiscal rules and introducing new rules on macroeconomic imbalances, known also as "six-pack", and "two-pack", the latter for the Euro area countries. Additionally, the Treaty on Stability, Coordination and Governance in the Economic and Monetary Union commonly referred to as the "Fiscal Compact Treaty" was signed and ratified by most of the EU member states.

\section{EUROPEAN SEMESTER}

From the start the main objective of the European Semester has been to ensure sound public finances, prevent excessive economic imbalances, boost investments and support structural reforms for jobs and growth. It can be seen from the results that our policies are beginning to pay off and that the economic recovery is happening in all member states. According to the European Commission (2016a), investments have started to pick up, and so has the employment rate, with 8 million new jobs created since 2013. The average EU unemployment rate stood at $8.6 \%$ in September 2016, reaching its lowest level since 2009. At the same time, the employment rate in the 20-64 age group is for the first time above that observed in 2008, at $71.1 \%$ in the $2^{\text {nd }}$ quarter of 2016 . Such an upward employment trend means that the $75 \%$ employment rate target set for the EU as a whole by 2020 may be within reach. With respect to public finances, the average EU government deficit has been declining, with several countries exiting the Excessive Deficit Procedure in recent years. The levels of government debt have also stabilized across the EU (ibid, 3).

The currently ongoing 2017 European Semester cycle was launched towards the end of last year with the release of the "autumn package", which includes the EU Annual Growth Survey (AGS) 2017 as a policy document outlining the economic and social priorities for the EU. As the European Semester remains the main instrument for the integrated annual coordination of national fiscal and macroeconomic policies in the EU, the AGS represents only one of its tools. In general, we are speaking about the surveillance tools available for EU economic policy coordination, which can be roughly split into three categories: surveillance of macroeconomic imbalances, surveillance of public finances and surveillance of Europe 2020 targets. 

(MIP), which starts each year with the release of the Alert Mechanism Report (AMR), published alongside the AGS by the European Commission for all EU member states. The AMR uses a scoreboard of selected indicators to screen EU countries for potential economic imbalances requiring policy action. The assessment also draws on other relevant economic, social and financial indicators not included in the main scoreboard. On this basis the AMR identifies countries that require further in-depth reviews, screening for vulnerabilities and macroeconomic risks. At the end of the review, the European Commission determines the presence or absence of imbalances as well as their extent.

The results of such in-depth reviews for identified countries form part of the European Semester "winter package", published each February, together with a detailed country report for each of the member states. In the 2017 cycle, 13 countries (Bulgaria, Croatia, Cyprus, Finland, France, Germany, Ireland, Italy, the Netherlands, Portugal, Slovenia, Spain and Sweden) were identified in the AMR as in need of an in-depth review, and are currently being assessed with respect to unwinding, persisting or aggravating (excessive) imbalances. In the second half of February 2017, the outcome of this assessment will be released together with the country reports (European Commission, 2016b).

Every country where imbalances or excessive imbalances were identified within the previous European Semester cycle is monitored throughout the year. This has also been the case for Croatia, where a detailed monitoring report on macroeconomic imbalances was presented to the working groups of the Council of the European Union in December last year, indicating the unwinding of internal and external imbalances, but also stressing that vulnerabilities still persist (European Commission, 2016c). The report emphasised that a number of structural reforms are yet to be implemented, such as the modernisation of public administration, pension and social protection systems reform, and the reform of regulated professions and services markets.

Structural reforms remain at the core of the European Semester process. They relate to all areas of public policy, including the more particular ones such as sustainable finance, the aim of which is to generate more innovative resource- and environment-friendly investments. We have just formed a high level expert group on the subject, which goes hand in hand with our work on the Capital Markets Union, creating a single market for capital in the EU (European Commission, 2016d).

Structural reforms in the more traditional policy areas such as more efficient public administration, fiscal stability, business climate, social protection, labor markets, education system and skills remain at center stage of the European Semester and are being closely monitored in all member states and at the level of the EU as a whole. 
The second category of tools within the European Semester is surveillance of public finances, implemented in line with the rules of the Stability and Growth Pact (SGP), through either its preventive or corrective arm, the latter being much better known due to the Excessive Deficit Procedure (EDP). The Council of the EU opened the procedure for Croatia at the end of January 2014 and recommended correction of the excessive deficit by 2016 . The recommendation includes headline deficit targets as well as matching annual improvements in the structural balance with expected consolidation measures. Next to deficit targets and in line with the Treaties and applicable legislation, the ratio of the government debt to GDP should be approaching the reference value at a satisfactory pace. The debt is considered to be sufficiently diminishing if the differential with respect to the reference value has decreased over the previous three years at an average rate of one twentieth per year as a benchmark, based on changes over the last three years for which data are available. The requirement under the debt criterion will be considered fulfilled if the European Commission's forecast indicates the required reduction in the differential over the three-year period encompassing the two years following the final year for which the data is available (EU Regulation $1177 / 2011)$. Croatia is expected to report on effective action taken to comply with the EDP in line with the commitments of the SGP in its 2017 convergence program expected to be released in April. Apart from Croatia, five other countries (France, Greece, Portugal, UK and Spain) have ongoing EDP procedures.

The objective of the preventive arm of the SGP is to ensure fiscal health. All countries are expected to reach their medium-term budgetary objective (MTO) (EU Regulation 1175/2011) or to be heading towards it by adjusting their structural budgetary positions at a rate of $0.5 \%$ of GDP per year as a benchmark. The countries should do more in favorable economic conditions, leaving room for flexibility when times get tough. Budgetary balance is defined in structural terms, taking into account the business cycle, disregarding the effects of one-off and other temporary measures as well as interest payments. MTO is complemented by the expenditure benchmark, which ensures sustainable growth in the net expenditure of a country.

The 2017 European Semester cycle introduced a novelty in the field of public finances in the European Commission Communication towards a positive fiscal stance of the euro area (European Commission, 2016e). In the absence of a fiscal stabilisation function, there is no built-in mechanism at the EU level to deliver a fiscal stance, which is appropriate for the euro area as a whole while being well balanced at the level of member states. The design of a positive fiscal stance is thus essentially a matter for the collective responsibility of the euro area member states. Our Communication calls for a moderately expansionary fiscal stance for the euro area, against the background of a resilient but modest economic recovery at this point in time. A fiscal expansion of up to $0.5 \%$ of GDP at the level of the euro area as a whole is considered desirable for 2017 , which is more expan- 
sionary than the intentions of the euro area member states, as noted in the submitted draft budgets (ibid:6).

\section{SURVEILLANCE OF EUROPE 2020 TARGETS}

The third category of the European Semester surveillance tools relate to Europe 2020, the EU strategy for smart, sustainable and inclusive growth (European Commission, 2010). It consists of a set of targets to be achieved by the EU as a whole and also by each member state with the objective of improving EU competitiveness while maintaining its model of social market economy and significantly improving its resource efficiency. Each member state sets its own national targets to be fulfilled by 2020 and the performance is easily measurable at the national as well as at the European level. The targets remain only politically binding, but they are an integral part of the stock-taking exercise of the European Semester every year. The targets act as policy anchors in the areas of employment, R\&D spending, reduction of greenhouse gas emissions, social inclusion and education.

\section{WHERE DO WE STAND TODAY?}

Chronologically, the winter package of the 2017 European Semester cycle will be followed by the member states' publication of the National Reform Programs, outlining structural reforms in April 2017. At the same time, countries will also release their Stability (euro area) or Convergence (non-euro area) Programs, setting out their medium-term fiscal policies. Taking into account the evaluation of both documents, the European Commission will publish its final documents of the 2017 cycle in its "spring package" in May. Its main document will be the Country Specific Recommendations (CSRs), which will include a review of the public finances in light of the submitted Stability/Convergence Programmes, taking into account the consolidated Eurostat data for the previous year. The CSRs will then be discussed (and endorsed) by the European Council in June and adopted by the Council (ECOFIN) in July 2017, when the 2017 European Semester will come to an end and the national implementation of reforms and budgetary drafting in member states will continue.

Policy design and its implementation in the framework of the European Semester is financially supported through several instruments, from EU Funds to other financial instruments such as the European Fund for Strategic Investment (EFSI) as well as the new Structural Reform Support Service (SRSS), which has been established within the European Commission to provide and financially support technical assistance for the implementation of the European Semester reforms.

The institutional and policy environment at the EU and the national level for the European Semester and its set of tools keeps changing. Most recently, the European Fiscal Board (Commission Decision 2015/1937) was established as an independent advisory board to the European Commission on fiscal matters. The Board will, among other things, evaluate the implementation of EU fiscal rules, advise on the fiscal stance appropriate for the euro area and cooperate with member 
states' national fiscal councils. The Council of the EU has endorsed the establishment of new National Productivity Boards - another tool to strengthen EU competitiveness. Banking union will hopefully soon reach its completion and the work on the Capital Markets Union has started. All of this and more will also be part of the European Commission's White Paper on the future of the EU, including on the Economic and Monetary Union, to be published in March 2017, coinciding with the $60^{\text {th }}$ anniversary of the Treaty of Rome.

For the past few years, we have been pursuing the "virtuous triangle" of structural reforms, responsible public finances and investments to deliver prosperity and social justice, and the EU has finally returned to moderate growth. Alongside positive signs of recovery, there is a pressing need to strengthen fairness and the social dimension of the single market in order to ensure that the weaker parts of societies also benefit from economic growth and to create a more inclusive society. Ensuring a promising economic future for all and safeguarding our way of life are priorities not only for the European Commission, but for all the EU member states as included in the "Bratislava roadmap" endorsed by 27 heads of state or governments in September 2016. To ensure more concrete steps in this direction, the European Commission has just concluded the consultation on the proposal for the European Pillar of Social Rights, which is all about guaranteeing a European social model that is fair and sustainable. By modernising the current EU legislation we want to support upward convergence through better education, skills and fair working conditions.

\section{CONCLUSION}

Over time the EU has strengthened economic governance by improving economic policy coordination and focusing European Semester instruments such as CSRs on their priority and scope. Although the European Commission remains responsible for many of the European Semester tools and documents, it is the EU member states that remain at the steering wheel when designing and implementing reforms and national budgets. What we wish to provide is guidance and assistance to countries that are not performing to a sufficient level. On the other hand, we also seek to recognise the best performing countries in certain policy areas through presentation of best practices.

There are many challenges facing the European Union today. The European Semester addresses not only the economic ones, but with its mechanisms and tools of surveillance and coordination often also touches upon political and democratic challenges. In this context, it is especially important to keep in mind that national specificities have to be taken into account in all areas of policy design and reforms; however, we firmly believe that only an integrated EU strategy for growth and jobs can result in a prosperous, fair and inclusive European Union for all. 


\section{REFERENCES}

1. Commission Decision (EU) 2015/1937 of 21 October 2015 establishing an independent advisory European Fiscal Board. Official Journal of the European Union, L 282/37.

2. EU Regulation $1175 / 2011$ of the European Parliament and of the Council of 16 November 2011 amending Council Regulation (EC) No. 1466/97 on the strengthening of the surveillance of budgetary positions and the surveillance and coordination of economic policies. Official Journal of the European Union, L 306/12.

3. EU Regulation 1177/2011 of 8 November 2011 amending Regulation (EC) No. $1467 / 97$ on speeding up and clarifying the implementation of the excessive deficit procedure. Official Journal of the European Union, L 306/33.

4. European Commission, 2010. Europe 2020 - A European strategy for smart, sustainable and inclusive growth. Available at: <http://ec.europa.eu/eu2020/ pdf/COMPLET\%20EN\%20BARROSO \%20\%20\%20007\%20-\%20Europe $\%$ 202020\%20-\%20EN\%20version.pdf>.

5. European Commission, 2016a. 2017 European Semester: Annual Growth Survey. Available at: $<$ https://ec.europa.eu/info/publications/2017-europeansemester-annual-growth-survey_en $>$.

6. European Commission, 2016b. 2017 European Semester: Alert Mechanism Report. Available at: <https://ec.europa.eu/info/publications/2017-europeansemester-alert-mechanism-report_en>.

7. European Commission, 2016c. Croatia-Review of progress on policy measures relevant for the correction of Macroeconomic Imbalances (December 2016). Available at: <https:/ec.europa.eu/info/files/croatia-review-progress-policymeasures-relevant-correction-macroeconomic-imbalances-december-2016_en>.

8. European Commission, 2016d. European Commission appoints members of the High-Level Expert Group on sustainable finance. European Commission - Press release. Available at: <http://europa.eu/rapid/press-release_IP-164502 en.htm>.

9. European Commission, 2016e. 2017 European Semester: Communication on Fiscal Stance. Available at: <https:/ec.europa.eu/info/publications/2017-european-semester-communication-fiscal-stance_en $>$. 